\title{
Combined therapy using suicide gef gene and paclitaxel enhances growth inhibition of multicellular tumour spheroids of A-549 human lung cancer cells
}

\author{
JOSE PRADOS ${ }^{1,2}$, CONSOLACION MELGUIZO ${ }^{1,2}$, ANA RAMA ${ }^{1,2}$, RAUL ORTIZ ${ }^{1,2}$, HOURIA BOULAIZ ${ }^{1,2}$, \\ FERNANDO RODRIGUEZ-SERRANO ${ }^{3}$, OCTAVIO CABA ${ }^{3}$, JOSE JUAN RODRIGUEZ-HERVA ${ }^{4}$, \\ JUAN LUIS RAMOS ${ }^{4}$ and ANTONIA ARANEGA ${ }^{1,2}$ \\ ${ }^{1}$ Institute of Biopathology and Regenerative Medicine (IBIMER), Granada, E-18071; \\ ${ }^{2}$ Department of Human Anatomy and Embryology, School of Medicine, University of Granada, Granada E-18071; \\ ${ }^{3}$ Department of Health Sciences, University of Jaén, Jaén E-23071; ${ }^{4}$ CSIC-Estación Experimental del Zaidín, \\ Department of Environmental Protection, Granada E-18008, Spain
}

Received January 17, 2008; Accepted February 28, 2008

\begin{abstract}
The low efficiency of conventional therapies in achieving long-term survival of lung cancer patients calls for development of novel options. The potential use of combined gene therapy is under intensive study. One approach uses the expression of genes encoding cytotoxic proteins that affect cellular viability. The gef gene from $E$. coli, identified as a member of a gene family encoding homologous cell-killing functions, encodes for a membrane protein with a toxic domain which leads to a decrease in the rate of tumour cell growth. To improve the antitumoral effect of the paclitaxel in lung cancer cells, we investigated a combined suicide gene therapy using this drug and gef gene in vitro, using A-549 lung cancer cells in culture and forming multicellular tumour spheroids (MTS). Our results showed that gef expression in A-549 cells led to an ultrastructural changes, including dilated mitochondria with clear matrices and disrupted cristae and cell surface alterations such as reduction in length and number of microvilli and cytoplasmic membrane evaginations. The use of paclitaxel in A-549 lung cancer cells transfected with gef gene enhanced the chemotherapeutic effect of this drug. Volume analyses showed an $87.4 \%$ decrease in the A-549 MTS growth after $96 \mathrm{~h}$ in comparison with control MTS. This inhibition was greater than that obtained using the gene therapy or chemotherapy alone. In conclusion, gef gene has a cytotoxic effect in lung cancer
\end{abstract}

Correspondence to: Dr Jose Prados, Instituto de Biopatología y Medicina Regenerativa (IBIMER), Department de Anatomía y Embriología, Facultad de Medicina, Universidad de Granada, E-18071 Granada, Spain

E-mail: jcprados@ugr.es

Key words: lung cancer, gene therapy, gef gene, combined therapy, cytotoxic therapy cells and enhances cell growth inhibition when used with paclitaxel. These results indicate that this combined therapy may be of potential therapeutic value in lung cancer.

\section{Introduction}

Lung cancer is the leading cause of cancer-related mortality in both men and women. Non-small cell lung cancer (NSCLC) represents about $75-80 \%$ of all lung cancers, and most of these patients are in advanced stage at diagnosis (1). Although chemotherapy has recently shown promising results in adjuvant strategies for early-stage patients (2) and some progress has been made in the treatment of locally progressive and advanced disease (3), latest studies suggest that a therapeutic plateau has been reached and that novel, more specific and less toxic therapeutic strategies are needed (4). A number of gene therapy techniques have been developed, but their safety and efficiency remain unsatisfactory. However, interest is growing in the development of combined approaches using gene therapy and local tumour irradiation or chemotherapy (5). The combination of gene therapy with various drugs has been shown to enhance tumour cell killing. Recently, novel advances in the combined use of suicide gene therapy and antitumour drugs have been reported in bladder cancer (6), pancreatic cancer (7) and breast or colorectal cancer (8). However, few studies of this type have been performed in lung cancer. In fact, classical strategies using a suicide gene e.g., herpes simplex virus thymidine kinase (HSV-tk), have shown beneficial effects but with some limitations (9). They are able to convert a non-toxic prodrug into a toxic metabolite, but the release of toxic metabolites and their bioavailability are two important shortcomings of the use of these systems (10). Therefore, increasing attention is being paid to the transfer of genes that are not dependent on the use of a prodrug. Our group recently developed a new cancer gene therapy strategy using a toxic gene from the chromosome of E. coli ( $\mathrm{gef}$ ) which does not need a prodrug to be effective in tumour cells 
$(11,12)$. The gef gene, a member of a gene family with homologous cell-killing functions, encodes a membrane protein of 50 amino acids that is anchored in the cytoplasmic membrane by the $\mathrm{N}$-terminal portion. The $\mathrm{C}$-terminal part is located in the periplasm (13). Mutagenesis studies have shown that this periplasmic portion encodes the toxic domain and that its dimerization is not essential for the toxic effect. Activation of this protein induces arrest of cellular respiration and cell death (14). Studies of suicide cassettes consisting of members of the gene family plus inducible promoters have documented their efficacy (15).

Based on the knowledge that the gef gene encodes a cytotoxic protein that binds to cell membranes, we investigated whether this gene can be used in a combined therapy with the antitumour drug paclitaxel in an experimental protocol to the treatment of lung cancer cells. Results obtained suggest that the combination of these treatments enhanced the anticancer effect and could be potentially used for cancer gene therapy approaches.

\section{Materials and methods}

Cell culture and MTS formation. The lung carcinoma cell line A549 (ATCC-CCL185) was grown with Ham's F12K (Sigma Chemical Co., St. Louis, MO), supplemented with $10 \%$ heat-inactivated foetal bovine serum (FBS), $40 \mathrm{mg} / 1$ gentamycin and $500 \mathrm{mg} / \mathrm{l}$ ampicillin (Antibióticos S.A, Spain). Cells were maintained in monolayer culture at $37^{\circ} \mathrm{C}$ in an atmosphere containing $5 \% \mathrm{CO}_{2}$. To generate multicellular tumour spheroids (MTS), exponentially growing monolayer A-549 cells were harvested by trypsinization and counted using a haemocytometer. Dead cells were excluded using trypan blue stain, then $10 \times 10^{3}$ cells/well were grown in a 24-well microplate (BD Biosciences) previously coated with $400 \mu 11.33 \%$ agarose type II in FCS-free medium and allowed to dry for $30 \mathrm{~min}$. Plates were incubated at $37^{\circ} \mathrm{C}$ in a $5 \% \mathrm{CO}_{2}$ atmosphere to promote aggregation and transferred onto a rocker designed for three-dimensional agitation (70 cycles/min) as described previously (16). Growth of the spheroids was monitored and measured to obtain a median relative volume (volume at day $\mathrm{x} /$ volume at day 0), as previously described by Boyd et al (17).

Vector construction. The gef gene was kindly provided by Dr J.L. Ramos from the Zaidín Experimental Station, CSIC, Granada, Spain. After its amplification using specific primers (sense 5'-ATGAAGCAGCATAAGGCGATG-3' and antisense 5'-TTACTCGGATTCGTAAGCCGTC-3') gef gene was subcloned into the pcDNA3.1 vector following manufacturer's instructions (Invitrogen). The resulting plasmid pcDNA3.1/ gef was confirmed by sequence analysis using the T7 primer 5'-TAATACGACTCACTATAGGG-3'. Plasmid DNA was amplified in E. coli DH5 $\alpha$ and purified by large-scale plasmid preparation using columns (Qiagen, Barcelona, Spain). DNA was dissolved in free TE buffer for storage. To optimize transfection conditions, the pcDNA3.1/lacZ encoding B-galactosidase under the CMV promoter was used as a positive control vector for transfection and expression. A control pcDNA 3.1 plasmid in which the gef gene was absent was used as a negative control. gef transfection in A-549. One day before transfection, confluent cells were seeded into 6 -well plates $\left(0.8 \times 10^{5}\right.$ cells per well). Briefly, a transfection mixture was prepared by adding $94 \mu 1$ of the serum-free medium and $6 \mu 1$ FuGENE-6 reagent (Roche Diagnostic, Barcelona, Spain). After 5 min of incubation at room temperature, $2 \mu \mathrm{g}$ of plasmid DNA (pcDNA3.1/gef) was added (ratio 2:6). The transfection mixture was incubated for $45 \mathrm{~min}$ at room temperature. A-549 cells, yielding approximately $70 \%$ confluence, were transfected with empty (control) or gef gene containing pcDNA vector. Cells were cultivated for $8 \mathrm{~h}$ at $37^{\circ} \mathrm{C}$, and the medium containing transfection mixture was then replaced with the growth medium. The $\beta$-galactosidase-positive cells were counted microscopically to determine the transfection efficiency which was between 40 and $50 \%$.

In vitro expression of gef gene. Upregulation of mRNA expression of gef cDNA was determined by RT-PCR. Total RNA was extracted from transfected (24, 48, 72 and 96 h) and parental cells with the Rneasy Mini kit (Qiagen), and cDNA was generated by means of the Promega reverse transcription system using total cellular RNA (1 $\mu \mathrm{g})$. PCR amplification of gef gene took place under the above-described conditions and was run on a $2 \%$ agarose gel and visualized by ethidium bromide staining. RNA integrity was assessed by amplification of $\beta$-actin mRNA (sense 5'-ATCATGTT TGAGACCTTCAA-3' and antisense 5'-CATCTCTTGCT CGAAGTCCA-3'). Images were scanned and analysed using a Bio-Rad documentation system (Quantity One Analysis Software). Relative gef mRNA expression was calculated as the ratio of gef to $ß$-actin.

Proliferation assays. Haemocytometer analysis and sulphorhodamine B proliferation assay were performed to evaluate the effects of gef gene on cell growth. Parental and transfected cells (including cells transfected with empty vector) growing in well plates were trypsinized after 24, 48, 72 and $96 \mathrm{~h}$ and collected. Then, cells were counted with a haemocytometer. Trypan blue dye exclusion was used to determine cell viability. The same experiment was repeated using sulphorhodamine-B (SRB). Cells were fixed with $10 \%$ trichloroacetic acid for $60 \mathrm{~min}$ at $4^{\circ} \mathrm{C}$ and stained with $0.4 \%$ sulphorhodamine $\mathrm{B} / 1 \%$ acetic acid by incubating for $10 \mathrm{~min}$ with constant shaking. Cells previously washed with $0.1 \%$ acetic acid were left in $10 \mathrm{mM}$ Trizma for $15 \mathrm{~min}$ at room temperature with constant shaking. Optical density was then determined using a Titertek multiscan (Flow, Irvine, CA) colorimeter at $492 \mathrm{~nm}$. Linearity of the SRB assay with cell number was tested for each A-549 cell stock before each cell growth experiment. A-549 cells transfected with empty vector were used in the proliferation assay as controls.

Measurement of Annexin V and PI staining. Annexin V and PI staining was used to assess apoptosis (Pharmingen, San Diego, CA). Briefly, medium was removed, then cells were washed twice with PBS and incubated in binding buffer (10 mM HEPES, $140 \mathrm{mM} \mathrm{NaCl}, 5 \mathrm{mM} \mathrm{KCl,} 1 \mathrm{mM} \mathrm{MgCl}$ $\left.1.8 \mathrm{mM} \mathrm{CaCl}_{2}, \mathrm{pH} 7.4\right)$ containing Annexin V-FITC $(25 \mu \mathrm{g} /$ $\mathrm{ml})$ and PI $(25 \mu \mathrm{g} / \mathrm{ml})$ in the dark for $15 \mathrm{~min}$ at room temperature. Then, $500 \mu 1$ binding buffer was added and cells 
were immediately processed with a FACScan flow cytometer (Becton-Dickinson, San Jose, CA).

Transmission electron microscopy (TEM) and scanning electron microscopy (SEM) analysis. Parental and transfected A-549 cells were fixed with $2.5 \%$ glutaraldehyde in $0.1 \mathrm{M}$ sodium cacodylate buffer ( $\mathrm{pH} 7.4)$ for $1 \mathrm{~h}$ at room temperature. Pellet and monolayer were post-fixed with $1 \%$ osmium tetroxide in 0.1 cacodylate buffer for $1 \mathrm{~h}$ at room temperature and dehydrated in ethanol. Cells were detached from culture vessel by rapid treatment with propylene oxide and embedded in Epon 812. After polymerization, the plastic was removed and ultrathin sections were cut parallel and perpendicular to the surface of the flask. Sections were contrasted with uranyl acetate-lead citrate and examined in a Hitachi H7000 transmission electron microscope. For SEM, adherent transfected and parental tumour cells on coverslips were fixed with $2 \%$ glutaraldehyde, dehydrated in graded concentrations of ethanol and dyed using the critical point method. These preparations were coated with platinum and observed under a Hitachi S-800 scanning electron microscope (Hitachi, Tokyo).

Combined therapy in MTS. MTS from A-549 cells were transferred, using a Pasteur pipette, from the 24-well microplate to a 96-well plate (one MTS per well) coated with agarose and containing $200 \mu \mathrm{l}$ of medium. MTS were transfected with pcDNA3.1/gef as reported above. Four groups of MTS were analysed: control MTS, transfected MTS, paclitaxel-treated transfected MTS and paclitaxel-treated non-transfected MTS. Paclitaxel was used at $10 \mathrm{nM}, 100 \mathrm{nM}$ and $1 \mu \mathrm{M}$ according to Monazzam et al (18). The experiment was carried out four times with six replicates in each group. The response to each anticancer treatment was evaluated by measuring MTS volume during treatment, as reported above.

Statistical analysis. SPSS 7.5 software (SPSS, Chicago, IL) was used for all statistical analyses. Results were compared by using the Student's t-test. All data are expressed as means $\pm \mathrm{SD}$. Differences were considered statistically significant at a P-value of $<0.05$.

\section{Results}

In vitro evaluation of gef expression. In vitro evaluation of gef gene expression was performed by RT-PCR. As shown in Fig. 1, an amplification fragment of $153 \mathrm{pb}$ was found in A549 cells transfected with pcDNA3.1/gef for different times, indicating the effectiveness and ability of the construction to be used in the subsequent in vitro experiment. To demonstrate the integrity of the RNA preparations, PCR was performed using $\beta$-actin primers (Fig. 1). Studies of the bands, normalized by comparison with the $\beta$-actin signal, showed that the highest gef expression occurred at 72 and $96 \mathrm{~h}$ after transfection (6.8- and 9-fold higher, respectively, vs. A-549 cells at $24 \mathrm{~h})$.

Inhibition of the A-549 growth rate by gef gene. After establishing that transfected A549 cells expressed gef transcripts, we analyzed the potential of gef gene to decrease the

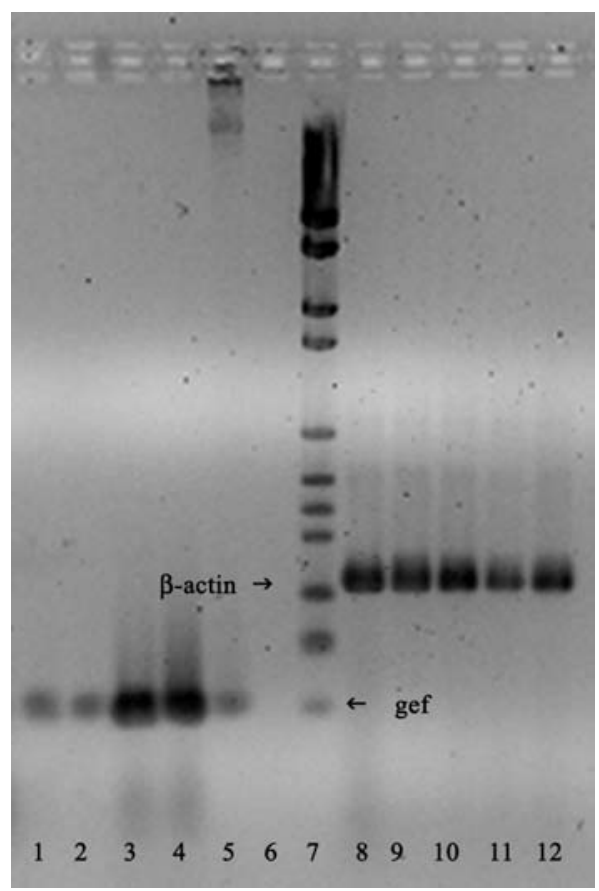

Figure 1. Determination of gef gene expression by RT-PCR. Total RNA isolated from transfected and parental A-549 lung cancer cells was transcribed to cDNA using reverse transcriptase PCR amplification as described in Materials and methods. Amplified PCR products of gef mRNA and $B$-actin mRNA were separated by $2 \%$ agarose gel electrophoresis and visualized with ethidium bromide. PCR of gef gene: lanes 1-4, transfected A-549 (24, 48, 72 and $96 \mathrm{~h}$ respectively); lane 5, pcDNA3.1/gef (positive control); lane 6, parental A-549 cells (negative control); lane 7, molecular weight. PCR of B-actin: lanes 8-11, transfected A-549 cells $(24,48,72$ and $96 \mathrm{~h}$ respectively); lane 12, parental A-549 cells.

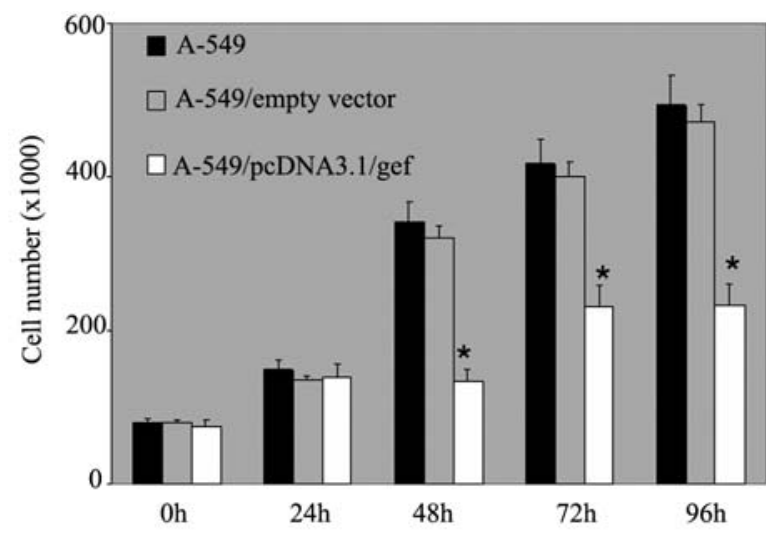

Figure 2. Effects of gef transfection on growth of A-549 cells. Parental A-549 cells and A-549 cells transfected with empty vector or pcDNA3.1/ gef were seeded at a density of $8 \times 10^{4}$ in plastic dishes and cultured for 4 days. Cell numbers were measured daily $(24,48,72$ and 96 h) by sulphorhodamine B assay. Values represent means \pm SD of quadruplicate cultures $\left({ }^{*} \mathrm{P}<0.05\right.$ compared with empty vector transfected cells).

growth of lung cancer cells. Cell growth was measured in A-549 cells transfected by either pcDNA3.1/gef (experimental group) or empty pcDNA3.1 (control group) at 24, 48, 72 and 96 h. As shown in Fig. 2, the growth of A549 cells transfected with the empty vector was similar to that of the parental cells. In contrast, A-549 cells transfected with pcDNA3.1/gef showed a significant and time-dependent decrease in growth. 

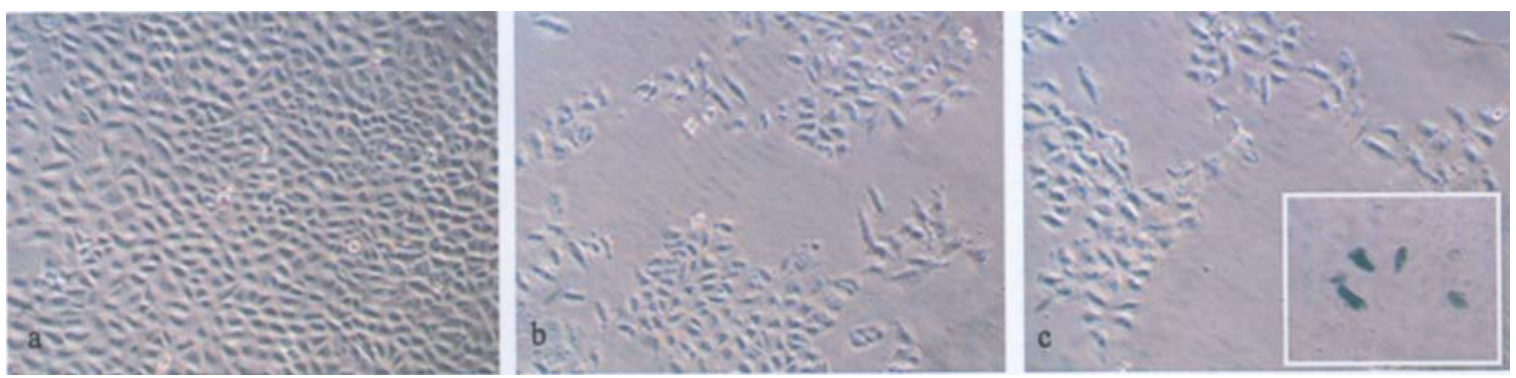

Figure 3. Phase-contrast photomicrographs showing morphology of parental and transfected A-549 cells. Parental A-549 cells (a) grew in clumps, were typically polygonal and formed a monolayer culture on the entire flask surface at $96 \mathrm{~h}$. In contrast, A549 pcDNA3.1/V5/His-gef transfected cells at $48 \mathrm{~h}$ (data not shown), $72 \mathrm{~h}$ (b) (cells stained with X-gal in corner) and $96 \mathrm{~h}$ (c) (x40) formed an irregular monolayer culture with the progressive presence of zones without cells.
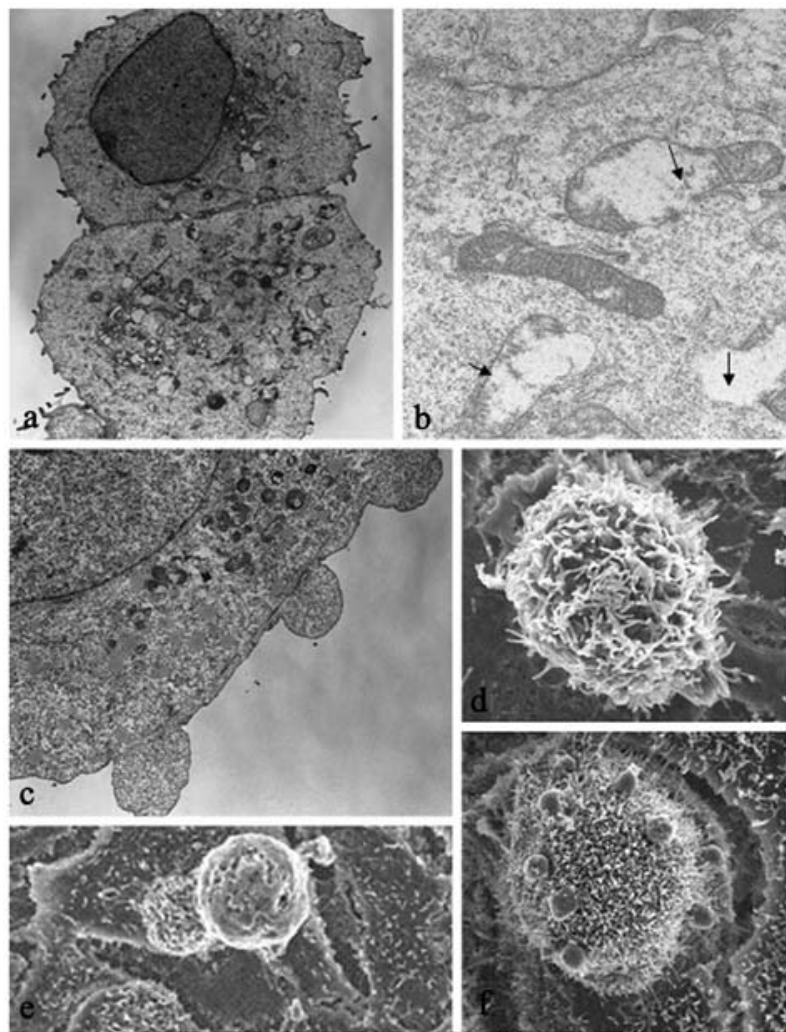

Figure 4. TEM and SEM analyses of A-549 cells. Conventional electron microscopy of parental A-549 cells (a) showed typical tumour cells with polygonal shape, large nucleus and light cytoplasmic complexion (x1100). Transfected A-549 cells showed dilated mitochondria with disrupted cristae (arrows) (b) (x12000) and cytoplasmic membrane evaginations (c) (x4400). Confocal microscopy of parental A-549 cells (d) showed numerous microvilli on cell surface. In contrast, transfected A-549 cells were characterized by progressive disappearance of microvilli (e and f) and membrane evaginations (f).

No significant differences were found at $24 \mathrm{~h}$ after transfection, then transfected cells showed a significant decrease in growth rate $(39 \%)$ vs. empty vector transfected cultures at $48 \mathrm{~h}$, with the largest decrease in the proliferation rate observed at 72 and $92 \mathrm{~h}$ (55 and $42.2 \%$, respectively).

Morphological characteristics of transfected A-549 cells. Light microscopy observations typically showed A549 lung cancer cells with polygonal shape and sheet-like pattern in
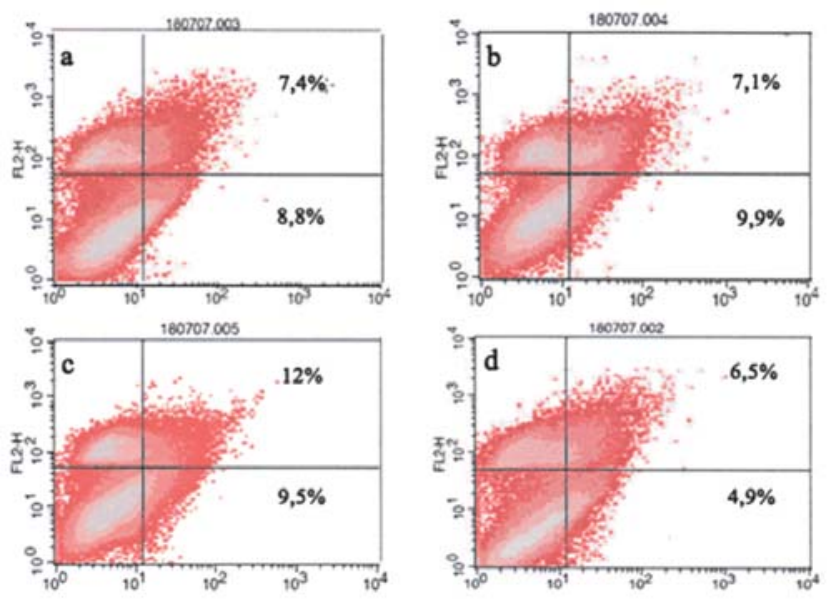

Figure 5. Fluorescence-activated cell sorting analysis of apoptosis induction by gef gene in A-549 lung cancer cells. Cells were stained with Annexin $\mathrm{V}$ and propidium iodide to evaluate apoptotic cell death, as described in Materials and methods. Representative images for comparisons between parental A-549 cells (a) and transfected A-549 cells at 48 h (b), $72 \mathrm{~h}$ (d) and $96 \mathrm{~h}(\mathrm{~d})$. These data are mean results of four separate experiments.

normal monolayer culture, compatible with their epithelial origin. Cells were attached to the bottom of the flasks with an irregular arrangement in confluent cultures, although some cells showed short cytoplasmic projections. Cultures of transfected cells with empty vector showed no morphological changes with respect to the parental cell line (data not shown). However, microscopic comparisons between control group cultures and cultures of cells transfected with pcDNA3.1/gef over four days showed a progressive loss of monolayer culture uniformity, with the presence of irregular zones without cells (Fig. 3). Conventional electron microscopy and confocal microscopy were used for ultrastructural analyses of transfected A-549 cells. Control cells showed the characteristic features of undifferentiated cells, i.e., polygonal shape, large nucleus and scant cytoplasm (Fig. 4a). In transfected A-549 cells, the most relevant ultrastructural features were the presence of dilated mitochondrias with clear matrices and disrupted cristae and of cell surface alterations, i.e., reduction in length and number of microvilli and appearance of cytoplasmic membrane evaginations (Fig. 4b and c). No compaction or segregation of chromatin was observed, indicating absence of apoptosis (data not shown). Similar 


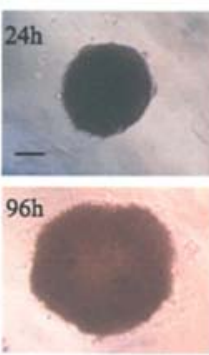

A

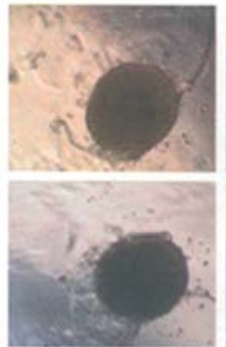

B

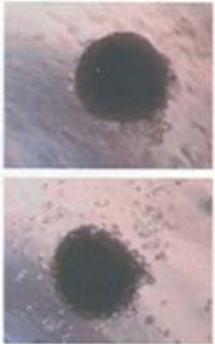

C3

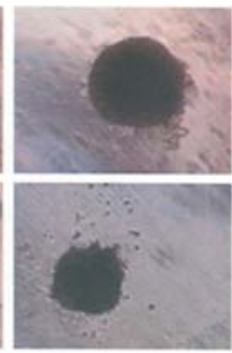

D3

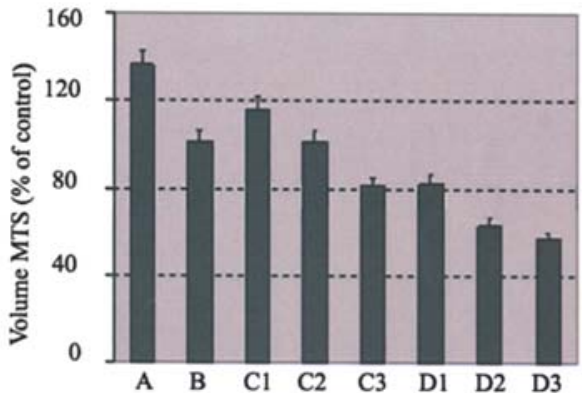

Figure 6. Analysis of the combined therapy (pcDNA3.1/gef/paclitaxel) in A-549 cells, using multicellular tumour spheroids (MTS). Growth of MTS was monitored by measurement of their cross-sectional area, calculating the median relative volume (volume at day $\mathrm{x} / \mathrm{volume}$ at day 0 ). The graph depicts percentage volume changes in MTS after 96-h treatment in each experimental group. Group A, control A-549 MTS; Group B, A-549 MTS treated with pcDNA3.1/gef; Group C, A-549 MTS treated with $10 \mathrm{nM}(\mathrm{C} 1), 100 \mathrm{nM}(\mathrm{C} 2)$ and $1 \mu \mathrm{M}(\mathrm{C} 3)$ paclitaxel; Group D, A-549 MTS treated with combined therapy pcDNA3.1/gef and $10 \mathrm{nM}(\mathrm{D} 1), 100 \mathrm{nM}$ (D2) and $1 \mu \mathrm{M}$ (D3) paclitaxel; Bar, $300 \mu \mathrm{m}$. These data are mean results of four separate experiments. Light microscopic image represents A-549 MTS of the experimental group A, B, C3 y D3.

morphological alterations were observed in SEM images. Cells with both morphological changes (microvilli reduction and membrane evaginations) were observed (Fig. 4e and f). In contrast, A-549 parental cells were characterized by numerous microvilli on their surface (Fig. 4d).

Apoptosis analysis. A-549 cells were studied by means of an Annexin V-FITC apoptosis detection kit to determine possible apoptotic cell death resulting from gef gene transfection. Treatment with empty vector had no significant apoptotic effect on these cells (data not shown), and no significant differences in apoptosis level were observed between transfected (24-96 h in culture) and control A-549 cells (Fig. 5). No typical apoptotic changes were observed under microscopy, as reported above.

Combined therapy with gef gene and paclitaxel in A-549 cells. The therapeutic potential of combined gef gene and paclitaxel therapy was evaluated in A-549 lung cancer cells. The response to each anticancer treatment was evaluated by measuring A-549 MTS volumes, as described above. The largest decrease in growth rate after treatment with pcDNA3.1/gef or paclitaxel was observed at $96 \mathrm{~h}$ (Fig. 6). At this time, a $35.2 \%$ volume decrease was observed in gef gene transfected A-549 MTS. With paclitaxel treatment, a dosedependent reduction in A-549 MTS volume was detected, with a decrease of $20.3,35$ and $54.6 \%$ vs. control MTS after administration of $10 \mathrm{nM}, 100 \mathrm{nM}$ and $1 \mu \mathrm{M}$ of paclitaxel, respectively (Fig. 6). However, a more effective inhibition of MTS growth was obtained by the combined therapy (pcDNA3.1/gef and paclitaxel treatments) than by each treatment alone. The effect of paclitaxel at different concentration was enhanced by gef gene expression but the largest reduction in A-549 MTS volume was obtained with $1 \mu \mathrm{M}$ paclitaxel. This treatment produced an $87.4 \%$ decrease in the MTS growth rate at $96 \mathrm{~h}$ vs. control MTS (Fig. 6).

\section{Discussion}

Despite therapeutic advances, conventional lung cancer therapy has failed to improve survival rates in NSCLC patients. The habitually late diagnosis and high mortality of lung cancer, alongside the ineffective and harmful effects of chemotherapy and radiotherapy, mandate the adoption of novel treatment approaches. Thus, research is in progress into combined modality treatment strategies for cancer, including gene therapy with anti-tumour drugs (19). The present study explored a combined therapy with gef suicide gene and paclitaxel as a new approach to the treatment of lung cancer.

To date, isolated gene therapy has not guaranteed the successful treatment of lung cancer. Gene therapy with antiangiogenic factors, proapoptotic genes or autologous tumour cells modified with an adenovirus vector have induced a partial response (5). Thus, HSV-tk/ganciclovir (GCV) treatment was shown to selectively kill lung cancer cells (20). However, despite the use of new specific promoters (e.g., INSM1) (21), this approach is limited by the release of toxic metabolites and their bioavailability (10). Moreover, the development of chemoresistance in lung cancer cells (such as GLC4) significantly changes GCV sensitivity, reducing the efficacy of HSV-tk/GCV (22). Therefore, therapeutic systems are required that are not dependent on the use of a prodrug. In fact, bacterial genes that encode toxins, viral genes, and even plant genes have been shown to be able to induce tumour cell death (23-25).

With this background, we assayed the gef gene in A-549 lung cancer cells. The gef protein is known to form pores in bacterial cell membranes, promoting host cell lysis, and it has demonstrated a cytotoxic effect in melanoma and breast cancer cells $(11,12)$. When we transfected gef gene in A-549 lung cancer cells, the number of surviving cells was significantly lower vs. control cells at 48-96 h, with the largest decrease in the proliferation rate observed at $72 \mathrm{~h}(55 \%)$. A similar growth inhibition effect was found in A-549 cells by Narumi et al (26) using a cytolytic pore-forming protein (perforin) that also binds to the tumour cell membrane. Interestingly, the decrease in tumour cell number observed in our experiments was not associated with apoptosis, despite a progressive loss of monolayer culture uniformity. Other nonmammalian genes used in cancer gene therapy induce cell death by a non-apoptotic mechanism (27). It was recently demonstrated that breast cancer cell growth is inhibited by bacteriophage $\lambda$-holin, a protein that can permeabilise the 
bacterial membrane (24). Forty-eight hours after induction cells became multinucleated, in some cases extensively vacuolated, and finally detached from the culture dish surface. These findings indicate that the cytotoxic effects of the $\lambda$-holin protein include alterations in cellular morphology preceding cell death. The gef gene diminishes the membrane potential, leads to membrane leakiness and also induces morphological changes (28). However, its specific mechanism of action in eukaryotic cells has not been elucidated. Eukaryotic cells fundamentally differ from prokaryotic cells in terms of their cellular structure, organisation, metabolism and membrane composition. Nevertheless, because the eukaryotic endomembrane system arose in an ancestral prokaryotic lineage (29), gef gene may act in cell organelle membranes. In fact, bacterial toxins such as Vibrio cholerae cytolysin or Helicobacter pylori VacA protein directly interact with the eukaryotic cytoplasm membrane $(30,31)$. This hypothesis is strongly supported by our ultrastructural findings in the transfected A-549 cells of dilated mitochondrias with disrupted cristae, cytoplasmic membrane evaginations and smaller and fewer microvilli.

After establishing the efficacy of the gef gene to affect the growth of human lung cancer cells, we investigated its use in a combined therapy with paclitaxel, a drug of choice for treating lung cancer. Addition of gene therapy strategies to conventional therapies appears to improve their effectiveness. Thus, the anti-tumour response was enhanced by combining chemotherapeutic drugs with HSV-tk in bladder cancer (6), with p53 in breast cancer (32) and with E2F-1 in melanoma (33). Combined therapy with docetaxel or paclitaxel and p53 or interleukin 12 genes improved outcomes in lung cancer (34). Paclitaxel, which has a known activity against a broad range of tumour types, also showed higher efficacy when combined with gene therapy in ovarian and metastatic breast cancers $(35,36)$. We tested the combination of paclitaxel and gene therapy in lung cancer cells by using A-549 MTS. This model mimics the real biological environment and gives a more relevant picture of the drug effects by including limitations in penetration, distribution and feedback mechanisms in cell signalling (37). Volume analyses of the A-549 MTS showed that the combined therapy induced significant MTS growth inhibition after $96 \mathrm{~h}$ in comparison with control MTS. The largest reduction was obtained with the use of gef gene and paclitaxel $1 \mu \mathrm{M}$. This inhibition was greater than that obtained using the gene therapy or chemotherapy alone. These results showed that the combination of gef gene and paclitaxel enhanced cell growth inhibition in A-549 MTS, suggesting its therapeutic potential in lung cancer. However, as in most gene therapy systems, gene delivery and selectivity for cancer cells remain a challenge. In this respect, retroviral vectors have the advantage of selectively transducing dividing cells and of integrating into the genome of the infected target cell. Recent developments in vector design, such as the reconstituting retroviral vector system (39), allow the generation of high-titre vector viruses expressing genes that encode cytotoxic products. By replacing the constitutively active viral promoters with tissue- or tumourspecific promoters (40), a targeted delivery of cytoxically acting gene products appears to be feasible. In summary, our data demonstrate the potential clinical relevance of a new combined therapy which could be used for lung cancer gene therapy.

\section{Acknowledgments}

We thank Dr R. Luque of the Oncology Service, Virgen de las Nieves Hospital, Granada, for providing the chemotherapeutic treatment. This study was supported by the Fondo Investigaciones Sanitarias Seguridad Social (FIS), Project no. PI041372.

\section{References}

1. Jemal A, Siegel R, Ward E, Murray T, Xu J and Thun MJ: Cancer Statistics 2007. CA Cancer J Clin 57: 43-66, 2007.

2. Depierre A, Milleron B, Moro-Sibilot D, Chevret S, Quoix E, Lebeau B, Braun, D, Breton JL, Lemarie E, Gouva S, Paillot N, Brechot JM, Janicot H, Lebas FX, Terrioux P, Clavier J, Foucher P, Monchatre M, Coetmeur D, Level MC, Leclerc P, Blanchon F, Rodier JM, Thiberville L, Villeneuve A, Westeel V and Chastang C: Preoperative chemotherapy followed by surgery compared with primary surgery in resectable stage I (except T1N0), II and IIIa non-small-cell lung cancer. J Clin Oncol 20: 247-253, 2002.

3. Hotta K, Matsuo K, Ueoka H, Kiura K, Tabata M and Tanimoto M: Addition of platinum compounds to a new agent in patients with advanced non-small-cell lung cancer: a literature based meta-analysis of randomised trials. Ann Oncol 15: 1782-1789, 2004.

4. Toloza EM and D'Amico TA: Targeted therapy for non-small cell lung cancer. Semin Thorac Cardiovasc Surg 17: 199-204, 2005.

5. Toloza EM: Gene therapy for lung cancer. Thorac Surg Clin 16: 397-419, 2006.

6. Shieh GS, Shiau AL, Yo YT, Lin PR, Chang CC, Tzai TS and Wu CL: Low-dose etoposide enhances telomerase-dependent adenovirus-mediated cytosine deaminase gene therapy through augmentation of adenoviral infection and transgene expression in a syngeneic bladder tumor model. Cancer Res 66: 9957-9966, 2006.

7. Deharvengt S, Rejiba S, Wack S, Aprahamian M and Hajri A: Efficient electrogene therapy for pancreatic adenocarcinoma treatment using the bacterial purine nucleoside phosphorylase suicide gene with fludarabine. Int J Oncol 30: 1397-1406, 2007.

8. Mavria G, Harrington KJ, Marshall CJ and Porter CD: In vivo efficacy of HSV-TK transcriptionally targeted to the tumour vasculature is augmented by combination with cytotoxic chemotherapy. J Gene Med 7: 263-275, 2005.

9. Wiewrodt R, Amin K, Kiefer M, Jovanovic VP, Kapoor V, Force S, Chang M, Lanuti M, Black ME, Kaiser LR and Albelda SM: Adenovirus-mediated gene transfer of enhanced Herpes simplex virus thymidine kinase mutants improves prodrug-mediated tumor cell killing. Cancer Gene Ther 10: 353-364, 2003.

10. Dachs GU, Tupper J and Tozer GM: From bench to bedside for gene-directed enzyme prodrug therapy of cancer. Anticancer Drugs 16: 349-359, 2005.

11. Boulaiz H, Prados J, Melguizo C, García A, Marchal JA, Carrillo E, Ramos JL and Aránega A: Inhibition of cell proliferation and apoptosis induction in human melanoma MCF7 cell line by gef gene. Br J Cancer 89: 192-198, 2003.

12. Boulaiz H, Prados J, Marchal JA, García A, Alvarez L, Melguizo C, Carrillo E, Ramos JL and Aránega A: Transfection of MS-36 melanoma cells with gef gene inhibits proliferation and induces modulation of cell cycle. Cancer Science 94: 564-568, 2003

13. Gerdes K, Poulsen LK, Thisted T, Nielsen AK, Martinussen J and Anderssen PH: The hok killer gene family in Gram negative bacteria. New Biol 2: 946-956, 1990.

14. Poulsen LK, Refn A, Molin S and Andersson P: Topographic analysis of the toxic gef protein from E. Coli. Mol Microbiol 5: 1639-1648, 1991

15. Molin SL, Boe LB, Jensen CS, Kristensen M, Givskov M, Ramos JL and Bej AK: Suicidal genetic elements and their use in biological containment of bacteria. Annu Rev Microbiol 47: 139-166, 1993. 
16. Odot J, Albert P, Carlier A, Tarpin M, Devy J and Madoulet C: In vitro and in vivo anti-tumoral effect of curcumin against melanoma cells. Int J Cancer 111: 381-387, 2004.

17. Boyd M, Mairs SC, Stevenson K, Livingstone A, Clark AM, Ross SC and Mairs RJ: Transfectant mosaic spheroids: a new model for evaluation of tumour cell killing in targeted radiotherapy and experimental gene therapy. J Gene Med 4: 567-576, 2002

18. Monazzam A, Razifar P, Simonsson M, Qvarnström F, Josephsson R, Blomqvist C, Langström B and Bergström M: Multicellular tumour spheroid as a model for evaluation of 18FFDG as biomarker for breast cancer treatment monitoring. Cancer Cell Int 6: 6, 2006

19. Fang B and Roth JA: The role of gene therapy in combined modality treatment strategies for cancer. Curr Opin Mol Ther 5: 475-482, 2003.

20. Määttä AM, Tenhunen A, Pasanen T, Meriläinen O, Pellinen R, Mäkinen K, Alhava E and Wahlfors A: Non-small cell lung cancer as a target disease for herpes simplex type 1 thymidine kinase-ganciclovir gene therapy. Int J Oncol 24: 943-949, 2004.

21. Pedersen N, Pedersen MW, Lan MS, Breslin MB and Poulsen HS: The insulinoma-associated 1: a novel promoter for targeted cancer gene therapy for small-cell lung cancer. Cancer Gene Ther 13: 375-384, 2006.

22. Van Dillen IJ, Mulder NH, Sluiter WJ, Meijer C, De Jong S, Loncarek J, Mesnil M, De Vries EF, Vaalburg W and Hospers GA: Consequences of chemoresistance for the herpes simplex virus thymidine kinase/ganciclovir-induced bystander effect in a human small cell lung cancer cell line model. Anticancer Res 25: 255-261, 2005.

23. McCray AN, Ugen KE, Muthumani K, Kim JJ, Weiner DB and Heller R: Complete regression of established subcutaneous B16 murine melanoma tumors after delivery of an HIV-1 Vpr-expressing plasmid by in vivo electroporation. Mol Ther 14: 647-655, 2006

24. Agu CA, Klein R, Lengler J, Schilcher F, Gregor W, Peterbauer T, Blasi U, Salmons B, Gunzburg WH and Hohenadl C: Bacterio-phage-encoded toxins: the lambdaholin protein causes caspase-independent non-apoptotic cell death of eukaryotic cells. Cell Microbiol 9: 1753-1765, 2007.

25. Zarovni N, Vago R, Soldá T, Monoco L and Fabbrini MS: Saporin as a novel suicide gene in anticancer gene therapy. Cancer Gene Ther 14: 165-173, 2007.

26. Narumi K, Kojima A and Crystal RG: Adenovirus vectormediated perforin expression driven by a glucocorticoid-inducible promoter inhibits tumor growth in vivo. Am J Respir Cell Biol 19: 936-941, 1998.

27. Katabi M, Yuan S, Chan H, Galipeau J and Batist G: The nonapoptotic pathway mediating thymidine kinase/ganciclovir toxicity is reduced by signal from adenovirus type 5 early region. Mol Ther 5: 170-176, 2002.
28. Ronchel M and Ramos JL: Dual system to reinforce biological containment of recombinant bacteria designed for rhizomediation. Appl Environ Microbiol 67: 2649-2656, 2001.

29. Emelyanov VV: Mitochondrial connection to the origin of the eukaryotic cell. Eur J Biochem 270: 1599-1618, 2003.

30. Coelho A, Andrade JR, Vicente AC and Dirita VJ: Cytotoxic cell vacuolating activity from Vibrio cholerae hemolysin. Infect Immun 68: 1700-1705, 2000 .

31. Szabó I, Brutsche S, Tombola F, Moschioni M, Satin B, Telford JL, Rappuoli R, Montecucco C, Papini E and Zoratti M: Formation of anion-selective channels in the cell plasma membrane by the toxin VacA of Helicobacter pylori is required for its biological activity. EMBO J 18: 5517-5527, 1999.

32. Cristofanilli M, Krishnamurthy S, Guerra L, Broglio K, Arum B, Booser DJ, Menander K, Van Wart Hood J, Valero V and Hortobagyi GN: A non-replicating adenoviral vector that contains the wild-type p53 transgene combined with chemotherapy for primary breast cancer: safety, efficacy and biologic activity of a novel gene-therapy approach. Cancer 107: 935-944, 2006.

33. Hao H, Dong YB, Bowling MT, Zhou HS and McMasters KM: Alteration of gene expression in melanoma cells following combined treatment with E2F-1 and doxorubicin. Anticancer Res 26: 1947-1956, 2006.

34. Nishizaki M, Meyn RE, Levy LB, Atkinson EN, White RA, Roth JA and Ji L: Synergistic inhibition of human lung cancer cell growth by adenovirus-mediated wild-type p 53 gene transfer in combination with docetaxel and radiation therapeutics in vitro and in vivo. Clin Cancer 7: 2887-2897, 2001.

35. Janát-Amsbury MM, Yockman JW, Lee M, Kern S, Furgeson DY, Bikram M and Kim SW: Combination of local, non-viral IL12 gene therapy and systemic paclitaxel treatment in a metastatic breast cancer model. Mol Ther 9: 829-836, 2004.

36. Janát-Amsbury MM, Yockman JW, Anderson ML, Kieback DG and Kim SW: Combination of local, non-viral IL12 gene therapy and systemic paclitaxel chemotherapy in a syngeneic ID8 mouse model for human ovarian cancer. Anticancer Res 26: 3223-3228, 2006

37. Kostarelos K, Emfietzoglou D, Papakostas A, Yang WH, Ballangrud A and Sgouros G: Binding and interstitial penetration of liposomes within avascular tumor spheroids. Int J Cancer 112: 713-721, 2004.

38. Schepelmann S and Springer CJ: Viral vectors for genedirected enzyme prodrug therapy. Curr Gene Ther 6: 647-670, 2006.

39. Poulsen TT, Pedersen N and Poulsen HS: Replacement and suicide gene therapy for targeted treatment of lung cancer. Clin Lung Cancer 6: 227-236, 2005. 